\title{
“IRRADIAR O SOPRO DO ESPÍRITO SOBRE O MUNDO": SENTIDOS DA PESQUISA SOCIOLÓGICA NO CATOLICISMO CARISMÁTICO
}

\author{
"Irradiate the breath of the spirit on the world": sense of sociological research in \\ charismatic catholicism
}

Emanuel Freitas da Silva ${ }^{1}$

\begin{abstract}
RESUMO
O presente artigo constitui-se de uma análise acerca dos sentidos conferidos por atores do campo religioso as pesquisas que versam sobre seus modos de vida, buscando compreender as ideias feitas por eles acerca de um saber (a pesquisa sociológica) que se pretende construir acerca das formas de experiência do religioso por eles vivenciada. Tomando como córpus de análise o universo da Comunidade Católica Shalom, oriunda do catolicismo carismático e sediada em Fortaleza (CE), o artigo tem como objetivo discutir nuances da pesquisa em meio religioso, destacando dois aspectos considerados fundamentais: a identificação do conceitochave para a compreensão do campo em questão e os sentidos produzidos pelos atores do campo acerca da pesquisa realizada. Tais sentidos os fazem produzir, argumenta o texto, uma certa episteme êmica acerca do saber sociológico que se busca produzir sobre eles. Relatos produzidos durante entrevistas, bem como contatos realizados após a pesquisa, e análise de material bibliográfico fazem parte do material de análise deste artigo, possibilitando a compreensão desse "saber nativo" acerca da pesquisa, permitindo a reflexão que aqui se opera acerca das dinâmicas da pesquisa em meio religioso.
\end{abstract}

Palavras-chave: campo religioso; sentidos; catolicismo carismático.

\begin{abstract}
This article consists of an analysis of the meanings given by actors in the religious field to research that deals with their ways of life, seeking to understand the ideas made by them about a knowledge (sociological research) that is intended to build on the forms of religious experience experienced by them. Taking as a corpus of analysis the universe of the Shalom Catholic Community, originating from charismatic Catholicism and based in Fortaleza (CE), the article aims to discuss nuances of research in a religious environment, highlighting two aspects considered fundamental: the identification of the key concept for the understanding of the field in question and the meanings produced by the actors in the field about the research carried out. Such senses make them produce, argues the text, a certain epic epistemic about the sociological knowledge that one seeks to produce about them. Reports produced during interviews, as well as contacts made after the research, and analysis of bibliographic material are part of the analysis material in this article, enabling the understanding of this "native knowledge" about the research, allowing the reflection that operates here about the dynamics of religious research.
\end{abstract}

\footnotetext{
${ }^{1}$ Doutor em Sociologia (UFC), Professor Assistente do Curso de Ciências Sociais (UECE-FACEDI), Professor dos Programas de Pós-Graduação em Sociologia e em Planeamento e Políticas Públicas (UECE). E-mail: emanuel.freitas@uece.br

REVISTARELEGENSTHRÉSKEIA - 2020 - UFPR
} 
Key words: religious field; sense; charismatic Catholicism.

\section{INTRODUÇÃO}

O estudo do fenômeno religioso, em suas diversas dimensões, exige o esforço de compreensão, por parte do pesquisador, das dinâmicas e nuances próprias do universo pesquisado. A começar pela definição do que o campo em análise considera como religioso, as formas de defini-lo e experenciá-lo, laços identitários e relacionais nele engendrados, léxico próprio ao campo e, mesmo, os significados do seu trabalho epistemológico para os sujeitos pertencentes ao universo pesquisado. Parte-se, como pesquisador, da vivência de outros sujeitos que, como experiência, constitui-se como “a vida” daqueles com quem pretende-se travar, ao longo da temporalidade daquela pesquisa (e, em alguns casos, para além desta), uma relação que lhe seja minimamente empática e proveitosa em termos epistemológicos.

Mesmo sabendo tratar-se aquela experiência religiosa de uma produção social e histórica, que toma a forma histórica e antropológica na qual o pesquisador se debruça, é-lhe necessário compreender as dinâmicas que a constituem como realidade religiosa para os membros e que, como tal, produz a estes mesmos membros, produzindo-lhes o mundo no qual existem e regulando suas existências e relações, inclusive as que os farão aproximar-se, ou não, do pesquisador.

No caso aqui em questão, apresentam-se algumas considerações da produção de conhecimento sociológico do campo religioso tomando como córpus de análise alguns elementos produzidos durante pesquisa que teve como objeto de análise (melhor seria dizer, como lócus epistemológico) a Comunidade Católica Shalom (CCSh), uma das mais importantes representantes do catolicismo carismático brasileiro, entre os anos de 2015 e $2018^{2}$.

O artigo tem como objetivo apresentar uma reflexão sobre os dois movimentos considerados mais importantes, durante essa pesquisa, para a produção de um conhecimento acerca do referido campo: primeiro, identificado o termo que estruturava o conjunto de relações mais importantes do campo, urgia distingui-lo em seus diversos elementos e, portanto,

\footnotetext{
${ }^{2}$ A pesquisa em questão resultou na Tese doutoral defendida no Programa de Pós-Graduação em Sociologia da Universidade Federal do Ceará, sob o título: A constituição burocrática da autoridade carismática - um estudo de caso sobre a Comunidade Católica Shalom, e pode ser encontrada em Silva (2018). Para a realização da pesquisa, foi de fundamental importância a produção de uma análise ancorada na sociologia weberiana (carisma dominação carismática, tipos religiosos, hierocracia etc), na sociologia bourdieusiana (poder simbólico e capital, campo religioso), na sociologia existencial de Berger (comunidades de vida, estruturas de plausibilidade e formas modernas de religião), dentre outros aportes teóricos do campo da Sociologia da Religião.
} 
compreendê-lo em sua polissemia; esse termo era "carisma”. O segundo movimento era compreender os sentidos que os membros da Comunidade davam à pesquisa em realização e que, a partir deles, geravam relações de empatia com o pesquisador, produzindo uma “necessária colaboração” destes, como veremos mais adiante, o que os fazia produzir uma certa episteme êmica acerca do saber sociológico que se buscava produzir sobre eles.

Assim sendo, o artigo estrutura-se da seguinte forma: primeiramente, apresenta-se, em linhas gerais, o campo observado, a Comunidade Católica Shalom (CCSh), destacando a problemática da pesquisa realizada; depois, é o momento de discutir a polissemia do conceito “carisma”, termo identificado como estruturador do universo pesquisado; por fim, apresentamse e discutem-se os sentidos da pesquisa para os membros da comunidade.

Em seu conjunto, o artigo pretende, a partir do caso particular analisado, contribuir com o universo das reflexões sobre o trabalho de campo dos pesquisadores de religião, suas dificuldades, os desafios da inserção no campo, a problemática da legitimidade frente aos “nativos” e, sobretudo, acerca dos sentidos que os sujeitos elaboram sobre a pesquisa.

\section{2-O CAMPO DE PESQUISA: A COMUNIDADE CATÓLICA SHALOM}

A CCSh foi fundada na cidade de Fortaleza, no ano de 1982, por um grupo de jovens que exerciam trabalho pastoral na Arquidiocese, tendo à sua frente o então estudante de Fisioterapia Moysés de Azevedo Louro Filho. Comprometidos com a espiritualidade da Renovação Carismática Católica (RCC) ${ }^{3}$, Moysés e os jovens por ele liderados resolveram dedicar-se mais enfaticamente à “evangelização dos jovens da cidade de Fortaleza”, conforme se narra/crê no histórico da Comunidade, e, primeiro por meio de uma lanchonete e uma livraria de produtos católicos, e depois pela ruptura com os pais e a vida secular, resolveram viver uma experiência comunitária deixando suas residências familiares, constituindo o que depois dariam o nome de “comunidade”, com uma dedicação exclusiva ao trabalho missionário.

No ano de 1998, a Comunidade alcançou seu reconhecimento diocesano, sob o governo de Dom Claúdio Hummes, até que em 2012, sob o papado de Bento XVI, recebesse o

\footnotetext{
${ }^{3}$ Movimento pentecostal católico iniciado no final dos anos 1960 nos Estados Unidos, que chegou ao Brasil logo em seguida. Inicialmente um movimento de leigos, logo se tornaria identidade de parte do clero. Em termos gerais, o movimento acredita na presença do Espírito Santo, hoje, tal como dera na igreja primitiva, com ênfase na manifestação de dons carismáticos (daí, renovação “carismática”), dos quais se sobressaem o de oração em línguas e o de cura. O centro de ação do movimento é o grupo de oração, de reunião semanal; mas, também, os grandes eventos em estádios e locais públicos dão marca à RCC. De início, momentos de tensão marcavam a relação dos membros com o clero, o que aos poucos foi sendo transformado em relações de cooptação e submissão. Uma excelente apresentação do movimento pode ser encontrada em CARRANZA (2009, 2000). 
reconhecimento pontifício, a partir do qual passa a ser nomeada como Associação Privada de Fiéis, inscrevendo-se no rol da assim chamadas Novas Comunidades ${ }^{4}$. Entre seus membros existem leigos consagrados no celibato, casais e sacerdotes (ou seminaristas). Com mais de 90 "missões”5, está presente em 30 países, nos cinco continentes (Brasil, Argélia, Tunísia, Madagascar, Cabo Verde, França, Guiana Francesa, Itália, Portugal, Espanha, Suíça, Londres, Alemanha, Hungria, Polônia, Toronto, Estados Unidos, Ásia, Israel, Paraguai, Uruguai, Equador, Peru, Chile, Bolívia, Moçambique, Argentina, Angola, Austrália, Suécia) e conta, atualmente, com 68 “obras de difusão” 6 .

O número de seus membros, na data em que este artigo é produzido, é de $7573^{7}$, divididos em 1199 na Comunidade de Vida e 6734 na Comunidade de Aliança, sendo a maior e mais importante comunidade carismática brasileira e, por isso mesmo, sendo a maior do mundo. Conta com 47 padres formados e 85 seminaristas em formação, Dos 12 padres ordenados em Fortaleza no ano de 2019, 8 pertenciam aos seus quadros. Em janeiro de 2020, o número de ingressantes na Comunidade de Aliança foi de 955, e na Comunidade de Vida 120, vindos dos Estados Unidos, Paraguai, Peru, Argentina, Chile, Portugal, África e Polônia, além dos mais diversos estados do Brasil.

\footnotetext{
${ }^{4}$ As "Novas Comunidades”, também denominadas “Comunidades de Vida e Aliança” são instituições, nascidas dentro da RCC, cujos membros ou dedicam-se inteiramente a elas (abandonando estudos, trabalho, vida familiar etc), no caso da "comunidade de vida"; ou fazem com ela uma "aliança", dedicando parte de seu tempo ao trabalho missionário da mesma. Enquanto os membros da RCC participam do movimento por meio dos grupos de oração ou dos ministérios, os membros das Novas Comunidades vão mais além e dedicam parte considerável de suas vidas ao serviço da Comunidade, mantendo com elas uma relação de ligação identitária, compreendida pela ideia de vocação, que os leva a professar votos de consagração institucional. As Comunidades de Vida (CV) são aquelas cujos membros abrem mão de tudo o que respeita à sua vida secular, "mundana" (trabalho, estudos, vida familiar, relacionamentos etc), desenvolvendo um estilo de vida consagrada próprio, com homens e mulheres abraçando votos de pobreza, castidade e pobreza. Suas residências comunitárias acolhem homens e mulheres de vários "estados de vida" (padres, casais e celibatários). Por sua vez, as Comunidades de Aliança (CA) são aquelas em que seus membros dedicam parte considerável de sua vida ao trabalho de evangelização e à vida comunitária, com encontro semanais de oração e formação religiosa, também fazendo os mesmos votos dos consagrados na Comunidade de Vida. Sobre as Novas Comunidades ver MARIZ (2009, 2000), OLIVEIRA (2014) e SAFIOTI (2009).

${ }^{5} \mathrm{O}$ termo "missão", no interior da CCSh, diz respeito ao espaço institucional da Comunidade, seu espaço físico em determinado lugar. Tal espaço compreende: um Centro de Evangelização (onde são realizados os grupos de oração, missas, reuniões, formação, trabalho burocrático, eventos etc), uma "casa comunitária” (onde moram os missionários da comunidade de vida) e as "residências comunitárias" (divididas por sexo e, em alguns casos, entre solteiros e casais). Advirto, porém, que em uma cidade por haver mais de uma "missão"; como é o caso de Fortaleza, onde, por exemplo, existem 29 Centros de Evangelização.

${ }^{6}$ Informações retiradas da página oficial da comunidade na internet (comshalom.org). Compreende-se como "obra de difusão” o envio de missionários da Comunidade para um determinado lugar, por dois anos, para realização de trabalhos missionários a pedido da diocese local. Passado esse tempo, pode-se ou não ser transformada em uma "missão", a depender de uma série de condições, sobretudo de ordem objetiva e de condições materiais de subsistência do trabalho dos membros.

${ }^{7}$ Conforme conversa com um dos membros do Setor Vocacional da CCSh.
} REVISTARELEGENSTHRÉSKEIA - 2020 - UFPR 
O trabalho missionário da CCSh compreende, além dos Centros de Evangelização, 4 emissoras de rádio administradas pela Comunidade, o Colégio Shalom (que oferece Ensino Fundamental e Médio, em Fortaleza, e no ano de 2016 conseguiu aprovação do MEC para a confecção de seu próprio material didático), a Faculdade Católica Rainha do Sertão, um albergue para moradores de rua, duas casas de assistência à viciados em drogas ilícitas, um programa semanal na TV Rede Vida e, em 2016, foi convidada pela Arquidiocese para administrar a Igreja do Carmo, no Centro de Fortaleza.

Inúmeros eventos promovidos pela Comunidade inscreveram-se na agenda católica, seja a nível local (como o festival musical Halleluya e o Renascer), nacional (Congresso Nacional de Jovens e Retiro para sacerdotes e seminaristas), ou mesmo internacional (como o Fórum Shalom). Livros e materiais produzidos pela Comunidade também transformaram-se em importante literatura no mercado consumidor de bens simbólicos da RCC, sendo sua cofundadora, Emmir Nogueira, autora de mais de 40 livros bastante difundidos no meio carismático. Seu fundador é membro do Pontifico Conselho para os Leigos, tendo sido convidado para o Consistório dos Bispos Europeus, em 2011, pelo então papa Bento XVI; um de seus padres, João Wilkes, possui assento no Dicastério para os Leigos, e Gabriela Dias, assessora apostólica da Comunidade, é a represente da América de língua portuguesa no recémcriado CHARIS, órgão subordinado ao Vaticano e que reúne sob sua administração todas as expressões da RCC, incluindo as Novas Comunidades ${ }^{8}$.

Uma diversidade de problemáticas sociológicas surge da observação atenta das particularidades da CCSh: as novas modalidades de pertença ao catolicismo (agora mediadas pela instituição “comunidade”, que parece substituir a paróquia ${ }^{9}$ ); identidade carismática e identidade católica (afinal, se é “carismático” ou se é “católico”?); coabitação entre sacerdotes, seminaristas, solteiros e casais (e, entre os dois sexos); relações de autoridade (fundadormembros) para além da obediência à hierarquia sacerdotal; formação de sacerdotes comprometidos com um novo ethos (o da comunidade); reinserção conservadora do catolicismo na arena político-partidária; atividade profissional-religiosa de membros na sociedade em geral; dentre outras coisas ${ }^{10}$.

\footnotetext{
${ }^{8}$ Em sua página oficial na internet (charis.internacional.pt) o órgão se apresenta como um instrumento que busca “promover e desenvolver a Renovação Carismática como uma corrente de graça na Igreja e para a Igreja”.

${ }^{9}$ Sobre isso consultar o estudo de Campos (2000).

10 Todas essas questões foram apresentadas em Silva (2019).

REVISTARELEGENSTHRÉSKEIA - 2020 - UFPR
} 
Mas, no que consistiu a problemática da pesquisa realizada que serve como material para este artigo? Como se deu o caminho da produção de um saber sociológico acerca da referida Comunidade?

Inicialmente, de forma ainda precipitada, com apenas algumas visitas ao campo e algumas leituras ainda esparsas, pensávamos que Moysés de Azevedo, o fundador da CCSh, e Emmir Nogueira, sua cofundadora (que possui maior expressividade dentro da RCC, para além da Shalom), figuravam como líderes religiosos que se constituíam como autoridades dentro da RCC.

Assim, numa Comunidade profundamente submissa à hierarquia, que orgulhava-se de sua proximidade com a mais alta cúpula do catolicismo, observava-se na distinção de seus fundadores, um leigo celibatário e uma mulher casada, a excepcionalidade de uma "graça” neles presente e (auto) reconhecida, que os tornava "profetas” de um "novo modo de ser Igreja”, de uma "renovação", que tomava forma na estrutura e na identidade da CCSh. Os dois líderes se constituiriam como um protesto silencioso à pretensão dos sacerdotes como "instrumentos por excelência” do serviço divino.

Pensando nisso, formulou-se a seguinte problemática: de que modo leigos constituemse como 'lideranças’ e 'profetas’ para, depois, legitimarem-se como 'autoridades religiosas', portadoras de um 'carisma', de uma 'nova identidade comunitária’ de pertença religiosa em meio a instituições marcadamente hierárquicas?

Essas concepções ${ }^{11}$ nos conduziram durante muito tempo, nos fazendo “crer”, num sentido religioso mesmo, quase a imitar os interlocutores, que havia uma mesma representação “carismática” das personas de Moysés e Emmir no interior da Comunidade, pontificando-se os dois como representantes de uma mesma excepcionalidade, entre si “dividida” e assim representada. O que faltava para desnaturalizar essa acepção, essa crença do pesquisador, era uma melhor imersão no campo, não apenas na escuta dos interlocutores, mas na leitura atenta daquilo que se dizia sem dizer, encontrando, assim, o verdadeiro "ponto de partida da Sociologia [...] a interrogação sociológica” (PAIS, 2013, p. 114).

Não seria, pois, em personas que a pesquisa deveria se concentrar, mas em processos sociais que produziram, como resultado final, tais personas, ou melhor, a persona crida como

\footnotetext{
${ }^{11}$ Que, por serem “pré-noções” acerca do universo estudado, e ofuscarem sua natureza de "sociologia espontânea” que produz “a ilusão do saber imediato” (BOURDIEU, PASSERON \&CHAMBOREDON, 1999, p. 23), deveriam ser afastadas para o bom desenvolvimento da compreensão sociológica que deveria empreender, sendo esta regra, “afastar-se das pré-noções”, uma regra fundante da prática sociológica (cf. DURKHEIM, 1987; PAUGAM, 2015).
} 
“carismática” por excelência (Moysés), portador do carisma (de fundação) que gerara o carisma (shalom) e que seduzia os vocacionados ao carisma (comunidade).

Isso nos levou, portanto, a formular a problemática em torno da produção social da liderança carismática de Moysés Azevedo: afinal, que processos societários produzem a crença numa liderança tida como carismática?

Embora tivéssemos abandonado, a partir das evidências que identificamos no campo, o recorte elaborado não poderia deixar, também por conta dessas evidências empíricas, de considerar que o termo nativo "carisma”, depois transformado em conceito-chave do campo, era de fundamental importância para a compreensão daquele universo.

Ao pensar nisso, lembramos das recomendações metodológicas de Bourdieu, Chamboredon e Passeron no que diz respeito à relação com os conceitos, sobretudo os “sistêmicos”, durante a realização de uma pesquisa:

[...] os conceitos mais capazes de desconcertar as noções comuns não detêm, em estado isolado, o poder de resistir sistematicamente à lógica sistemática da ideologia: ao rigor analítico e formal dos conceitos ditos "operatórios” opõe-se o rigor sintético e real dos conceitos que receberam a designação de sistêmicos porque sua utilização pressupõe a referência permanente ao sistema completo de suas inter-relações (BOURDIEU; CHAMBOREDON. PASSERON, 2015, p. 47)

Estava claro, pois, que o conjunto de relações (estruturais, identitárias, organizacionais, eclesiais) que permeava as dinâmicas do cotidiano da CCSh passavam pela ideia de carisma e por seus desdobramentos, o que fazia deste conceito o elemento central para análise.

Foi assim que, durante o desenvolvimento da pesquisa com membros da referida comunidade, dois elementos mostraram-se de vital importância para nossa compreensão sociológica, sem os quais a aventura de pesquisa estaria comprometida: a compreensão do termo mais-que-importante no cotidiano (diria mais, na estruturação) da vida e da identidade dos membros, termo este ao qual nos referimos aqui como "conceito-chave” para o mergulho, por assim dizer, no universo semântico da comunidade; e os sentidos que estes produziram acerca da pesquisa então realizada, nas diversas ocasiões em que estivemos entre eles. Vejamos, pois, a seguir.

\section{3- A EPISTEME E A POLISSEMIA DO “CARISMA”}

Compreender as diversas relações existentes dentro de uma comunidade do catolicismo carismático lança o pesquisador diante de um termo, que para os nativos é uma "realidade”, um tanto quanto familiar ao léxico sociológico: carisma. A começar pelo qualificativo que nomeia 
o movimento e do qual crê ser a sua identidade: Renovação “Carismática” Católica; depois, por logo de início sabermos que as Novas Comunidades, como é o caso da Shalom, identificam-se como portadoras de um chamado, uma vocação à qual nomeiam como “carisma”, o seu carisma, aquilo que lhes é próprio, servindo-lhes, pois, como identidade. Identidade carismática.

Mas, por qual razão? A CCSh define-se como um “carisma” dentro da Igreja Católica e, sendo um carisma, foi fundada por Moysés Azevedo, a quem se atribui o "carisma de fundação" da Comunidade que, por sua vez, existe dentro da experiência de "renovação dos carismas”, identidade da RCC. Eles viveriam, ou seriam, ou portariam o carisma shalom.

Assim, pois, um primeiro movimento é o que nos põe diante de um termo - carisma que também possui usos dentro da Sociologia; um termo com dupla semântica: êmica e epistemológica. Mas, para dinamizar ainda mais a pluralidade do termo, sua polissemia, que não era apenas dual (êmica X epistemológica), mas, dentro do universo êmico, seria ainda mais plural.

Logo, um itinerário de pesquisa traçava-se diante de nós à medida em que decidíamos por perscrutar, sociologicamente, o universo da CCSh: o que vem a ser carisma? ${ }^{12}$ Como definilo? Onde identificá-lo?

Haveria uma compreensão de “carisma” eclesial, por assim dizer, do catolicismo; uma compreensão da RCC, que poderia chamar de carismática; e uma compreensão das Novas Comunidades, que poderíamos apropriadamente chamar de êmica, uma vez que era a forma utilizada pela CCSh. Portanto, o percurso da pesquisa passaria, necessariamente, pela devida compreensão e definição do termo carisma, central para o grupo pesquisado, nos seguintes contextos: eclesial, carismático, novas comunidades, comunidade shalom. E, após isso, as relações entre tais definições e a definição sociológica.

Sociologicamente, o carisma define-se como um conjunto de "dons considerados como sobrenaturais, não acessíveis a todos” (WEBER, 1979, p.283), ou como

[...] uma qualidade pessoal considerada extracotidiana (...) em virtude da qual se atribuem a uma pessoa poderes ou qualidades sobrenaturais, sobre-humanos, ou então se a toma como enviada por Deus, como exemplar, como líder (WEBER, 2012, p. 159).

Assim, o portador daquilo que é considerado como “carisma” ou como "algo extraordinário”, “excepcional”, opõe-se à toda forma de manutenção do cotidiano e sua normalidade, ou mesmo à toda uma tradição. Ele lidera um grupo, uma coletividade ou uma

\footnotetext{
12 Em Silva (2019a) pode-se encontrar uma discussão mais pormenorizada sobre a questão sociológica em torno da definição de carisma.

REVISTARELEGENSTHRÉSKEIA - 2020 - UFPR
} 
comunidade por conta de seu carisma, e precisa a todo instante provar sua excepcionalidade, transcendendo-se a si mesmo e à realidade que pretende "renovar”, "magicizar”, uma vez que a prova do carisma que lhe pertence é uma condição sine qua non para a manutenção de sua dominação carismática, de sua legitimação, sob o risco de perder o reconhecimento que tem perante à coletividade (Weber, 2012).

O líder carismático (como fomos percebendo que Moysés aparecia para seus liderados) é, pois, um criador. Confere existência a uma coletividade - seus seguidores - a partir daquilo que mostra, enuncia e anuncia. Anunciar, nele e para ele, é enunciar, tornar algo real a partir de suas palavras. Isso porque o líder carismático torna-se a objetivação do próprio carisma, o carisma incorporado, encarnado, personificado. E, ao incorporá-lo objetivamente, interdita tal dádiva a outros, seus dominados, mantendo-se a si mesmo como extraordinário, revolucionário, carismático.

Eclesiologicamente, a melhor e mais sintética definição de carisma que encontramos na teologia católica foi a seguinte: “entendemos por carisma um dom interior, uma amplitude liberada pela Espírito Santo, revestida de força por Ele e posta a serviço da edificação do corpo de Cristo” (JUANES, 2001, p. 55). Assim sendo, para a catolicidade “carisma” é tudo aquilo que, como interioridade, crê-se ter sido dado por Deus para o serviço eclesial. Contudo, uma definição mais abrangente do que a Igreja entende como carisma, a partir dos usos que do termo se fizeram a partir do Concílio Vaticano II, é-nos dada a seguir:

\footnotetext{
No decurso dos trabalhos conciliares, utilizou-se a palavra "carisma" em referência à vida religiosa, falando de "caráter carismático da vida de perfeição evangélica", de "religiosos realmente carismáticos", de "dons carismáticos concedidos aos fundadores" e de "caráter carismático dos institutos religiosos". Porém, nos textos conciliares, a palavra "carisma" não parece ter um significado preciso, porque às vezes parece indicar dons espetaculares e, às vezes, pelo contrário, qualquer coisa que proceda de Deus. Num texto específico (Lumem gentium), o Concílio distinguiu entre dons "hierárquicos" e dons "carismáticos", e submeteu os carismas à autoridade da Igreja (ROCCA, 2010, p. 28).
}

Assim, durante a busca pela definição do termo carisma no interior do catolicismo, longe de proceder com uma investigação sobre o itinerário lexical do termo, concentramo-nos no modo como a instituição pensa-o contemporaneamente, o que nos fez chegar ao seguinte: entende-se por carisma aquilo que é dado ao fiel batizado para servir à Igreja, seja por meio do serviço (que vai da pastoral, passando pela vida consagrada nos institutos à ordenação sacerdotal), seja por meio da produção de novos modos de se pertencer à instituição. 
No interior da RCC, que é um movimento de cunho pentecostal ${ }^{13}$ dentro do catolicismo, se crê que a renovação espiritual só é possível com a importância conferida pelo fiel à vivência dos dons carismáticos ${ }^{14}$, entendidos como dons do Espírito Santo. Tais dons são os “carismas”, dádivas de Deus que devem ser usadas por aqueles que tiveram o privilégio de recebê-las, quando da “efusão do Espírito Santo”, marca maior da RCC:

Para o movimento, sem o Espírito e os carismas não há Igreja Católica. Assim, não existe cristão que não tenha algum carisma, sendo que para o movimento cada cristão é um carismático. O movimento estabelece um processo para explicar a entrada do indivíduo na vida cristã que passa pelo batismo, confirmação e eucaristia tidos como meios de iniciação. O carismático se considera um representante de uma nova realidade, o Espírito Santo, e tem sua marca na experiência com este Espírito (SAFIOTI, 2009, p.226).

Essa dimensão “carismática”, por assim dizer, da RCC, que lhe confere a identidade dentro do catolicismo, necessita do exercício cotidiano dos dons carismáticos, seja nas reuniões de grupos de oração, nos eventos de massa, na oração individual dos fiéis ou mesmo nas missas que são celebradas por sacerdotes ligados ao movimento ou celebradas nos espaços pertencentes à RCC.

Para as Novas Comunidades, por sua vez, carisma diz respeito, antes de tudo, a uma experiência pessoal vivenciada pelo fundador da comunidade em questão, o líder portador do carisma em essência, que aos poucos vai “radicalizando” sua experiência e aglutinando em seu redor outros sujeitos que serão "moldados" a partir daquilo que enunciará como "vontade divina” para si (carisma de fundação) e para aqueles que vierem juntar-se a si (carisma como vocação) ${ }^{15}$.

Como analisamos em outro lugar ${ }^{16}$, a pessoa do fundador porta para os membros da comunidade uma excepcionalidade que, crida como tal, o produz como um elo de ligação entre o mundo sagrado e o mundo profano (o fundador é o laço que une os membros à vontade de Deus, uma vez que esta é expressa para eles naquilo que “Deus revela” ao fundador). Segundo Gislaine, co-fundadora da Comunidade Óasis (RS), o carisma do fundador:

\footnotetext{
13 “[...] o pentecostalismo e a Renovação Carismática Católica podem ser considerados uma expressão 'mística' do cristianismo, e, como tal, têm sofrido as críticas historicamente feitas a essa vertente no universo cristão. Por entender que os indivíduos podem ter contato com o sagrado sem a mediação institucional, essa espiritualidade ameaçaria não só a autoridade religiosa institucionalizada, mas também o saber teológico racional. Ao definir a espiritualidade pentecostal como uma religião do "eu" e "encantada", voltada para soluções milagrosas de problemas pessoais e emocionais, os estudiosos desses movimentos fornecem a seus críticos do campo religioso argumentos pertencentes à gramática das ciências sociais” (MARIZ, 2016, p. 11).

${ }^{14}$ São dons dos quais o apóstolo Paulo fala em I Corintíos 12: sabedoria, ciência, fé, cura, milagres, profecia, discernimento, línguas e interpretação das línguas.

${ }^{15}$ Cf. Nogueira (2012).

${ }^{16}$ Silva (2019, 2019a).
}

REVISTARELEGENS THRÉSKEIA - 2020 - UFPR 
[...] é o carisma da comunidade [...] Quando Deus pensou o nosso fundador, ele pensou em cada um de nós em nossa existência, ele pensou em “Oásis’, eu não existira se eu não fosse "Oásis". Nós temos o mesmo DNA. [...] A Chica, como fundadora, me dá a capacidade de eu saber quem eu sou, o que Deus pensou para mim, ela vai me revelando, vai me deixando claro o projeto de Deus a meu respeito. Não basta viver na Comunidade, mas sim ser da comunidade, ser daquela família. O nome da Comunidade passa a ser o meu nome. [...] A ponto de as pessoas me identificarem, dizerem assim: “ela só pode ser da Oásis”. O carisma é uma verdade. [...]. (Gislaine Duque $)^{17}$.

Observemos que, segundo a pregadora, não existe comunidade sem o fundador, pois ela nada mais é do que aquilo que fora a ele "revelado”. Há uma espécie de "DNA”, um código "genético” que une cada um dos membros da comunidade a seu líder, ligação essa que expressa o "projeto de Deus”, que existe desde sempre como uma "verdade” acerca dos sujeitos daquela coletividade, pois olhar para cada um deles é olhar para o “carisma”, e olhar para o carisma é olhar para o fundador. Logo, os sujeitos perdem suas identidades individuais para incorporarem a identidade comunitária que está centrada na persona do fundador.

Algumas declarações ${ }^{18}$ de membros da CCSh, colhidas durante a pesquisa doutoral realizada e que serve de córpus de análise para este artigo, expressam exatamente essa percepção:

[Moysés é] nosso fundador porque Deus deu a ele uma inspiração de algo novo na Igreja [...] colocou no coração dele e chamou outras pessoas que têm o mesmo chamado do que ele [...] ele é quem tem a intuição primitiva de dizer o que é ou não é condizente com essa inspiração primeira. [...] O carisma é ele e os outros chamados, os que estão dentro da Comunidade (Entrevistado 1).

Se não fosse a Comunidade eu não sei onde eu estava. A Comunidade dá sentido à minha vida (Entrevistado 2).

[Na Comunidade Shalom) Eu descobri o que eu sou! (Entrevistado 3) (Grifos nossos).

A centralidade da "graça fundante”, do carisma de fundação, por assim dizer, constitui-se o elemento de grande valia para a crença na carismaticidade do líder (ou dos líderes) mas, sobremaneira, para evitar dissidências que possam vir a ocasionar abalos na estrutura comunitária ou mesmo na crença da superioridade do fundador. Germana Perdigão, consagrada há 35 anos na comunidade de aliança da CCSh, refere-se ao tema nos seguintes termos:

O "espírito do fundador" deve nortear, em conjunto com os outros aspectos, sua vivência e “jeito de ser e de viver o carisma dado pelo Espírito Santo”. Esta dimensão da sua vida permeia toda a sua existência, assim como o modo de conduzir a Obra. O Autor de todas as graças teceu o Moysés com um coração de criança, mas alma de gigante, "violento" em suas decisões. Jamais o vimos com "meios termos”, “com sobes e desces” em suas decisões por Deus e pela salvação dos homens. Em todos

\footnotetext{
${ }^{17}$ Disponível em https://www.youtube.com/watch?v=ut-RCjZm2GI. Acesso em 14/12/2016.

${ }^{18}$ Durante a realização da referida pesquisa, fizemos um total de 27 entrevistas, totalizando mais de 60 horas de material. O fundador, a cofundadora, membros com mais de 20 anos de pertença comunitária, ex-membros (rompidos e simpatizantes) e um arcebispo compuseram esse número, o que nos deu uma boa visão acerca da CCSh.
}

REVISTARELEGENSTHRÉSKEIA - 2020 - UFPR 
esses anos aprendemos com ele que o amor vai além dos sentimentos, do esquecimento de si, que não esbarra nas limitações e fraquezas humanas (PERDIGÃO, 2007, p. 17).

Sem dúvida alguma, a crença peculiar da RCC de que todos os batizados são portadores dos dons carismáticos do Espírito Santo permite o aparecimento de líderes cridos como carismáticos que, a partir da legitimação que uma comunidade lhes confere, adquirem liberdade para gerar uma coletividade de acordo com as convicções que acreditam ser de "inspiração divina”, aparecendo, assim, como um “eleito”, “escolhido"19.

Para Max Weber, a problemática sociológica do carisma apontava para o processo de instituição de uma liderança e uma autoridade, em que se podia verificar um processo coletivo, ou comunitário, de atribuição de um caráter extraordinário (“carismático”) a um líder, uma persona, no qual se imbuíam processos de legitimação e de institucionalização. Convém, contudo, ressaltar que, em tempos de (neo)pentecostalismo, e de RCC, grande parte da experiência religiosa cristã tem sido assentada nessa crença de "poder carismático”, ora através de "especialistas" do divino, ora por “acesso direto ao Espírito Santo" (CAMPOS\&MAURICIO JUNIOR, 2013).

A característica que acompanha os relatos fundacionais das Novas Comunidades é, pois, a crença no "chamado encantado do líder”, ou seja, a crença em sua experiência mística, que é estendida a todos aqueles que, a posteriori, juntar-se-ão a ele no “chamado vocacional”. O engajamento dos membros "é o engajamento a partir da palavra de um líder carismático" (MIRANDA, 1999, p. 54). Uma vez que nascem em torno da "verdade revelada” a um fundador, tais comunidades encaram-na (a esta "revelação”) como um carisma particular (no sentido de um chamado, uma vocação, uma missão específica, uma predestinação), que formula sua identidade no seio da Igreja ${ }^{20}$. Este chamado diz respeito à missão para a qual se é vocacionado e aos meios necessários para que a Comunidade em questão exerça seu papel eclesial.

Na Shalom, carisma é entendido como a própria comunidade que, longe de se definir como uma estrutura humana ou material, define-se como uma vocação. A Comunidade Shalom

\footnotetext{
${ }^{19}$ Conforme dito em várias das entrevistas realizadas. Como lembra Willaime, ao comentar a sociologia de Weber, o líder carismático “impõe sua legitimidade por meio de uma revelação que ele mesmo divulga” (2012, p. 54), criando, assim, um "vínculo”, palavra esta que, segundo a afirmação de SENNETT (2001, p.14), permite a compreensão da ideia de "ligação”, mas também de “servidão, limite imposto".

${ }^{20}$ Assim, o "carisma” da Canção Nova seria a evangelização por meio dos mass media, assim como o "carisma” da Recado seria a evangelização por meio das artes, e o da Toca de Assis o cuidado com os pobres.

REVISTARELEGENSTHRÉSKEIA - 2020 - UFPR
} 
é o lugar daqueles que possuem a vocação shalom, e destes o primeiro a possuir a vocação, ou o carisma, é o seu fundador.

Ciente de que a compreensão do que venha a ser o “carisma” marcava o universo simbólico sob o qual os membros da CCSh vivenciavam suas identidades, indagou-se dos entrevistados qual significado havia para eles afirmar que Moysés era o "fundador carismático" da Comunidade Católica Shalom. Ideias como a de "predestinado” para o cargo, a identidade entre ele e o carisma, portador de uma "graça especial”, "fonte” e "segurança” para os membros, encarna a "verdade" do carisma, alguém que é fundador por "acreditar mais" que todos os outros. Algumas das respostas estão abaixo: Ele recebe de Deus uma graça, no sentido de alguém que tem esse chamado na
identidade dele, uma graça que ultrapassa enormemente ele, ele vai dizendo sim, e é
levado por essa graça. E depois vem os seus seguidores (Entrevistado 1)

O carisma é ele e os outros que são chamados dentro da Comunidade. Moysés é Shalom (Entrevistado 2).

O espírito do fundador é o espírito do carisma (Entrevistado 3).

Ele tem o carisma de fundador, e nós o carisma de fundação [...] Quando ele morrer, cessou as coisas novas (Entrevistado 4).

O carisma passa por ele, ele é um eleito [...] alguém que Deus quer, teria que questionar a Deus porque ele e não outro. Com Moysés vivo ninguém queria outra pessoa governando a Comunidade (Entrevistado 4) (Grifos nossos).

$\mathrm{O}$ fato de o fundador estar junto de seus liderados aumenta a vitalidade daquilo que se crê ser o carisma. "Enquanto o Moysés estiver vivo o carisma está se revelando”, “é uma graça morar na mesma casa que o fundador”, “é muito edificante vê-lo fazer as pequenas coisas, as mais cotidianas”, “ele é uma pessoa verdadeiramente santa, embora não goste que falemos disso": essas foram algumas das afirmações colhidas durante as entrevistas realizadas. A vocação dos membros da Comunidade se espelha na vocação-primeira do fundador, no carismaprimeiro dele, que é ele, “encantando-se” ${ }^{21}$ por sua forma de viver a realidade por ele mesmo enunciada, escrita, definida, formulada, conforme pôde se observar em diversas entrevistas. $\mathrm{O}$ fundador corporifica, pois, o próprio carisma ao qual se foi chamado ${ }^{22}$. Ele assume, no interior da Comunidade, uma dimensão de materialidade da força sagrada do qual creem ser partícipes,

\footnotetext{
${ }^{21}$ Usamos o termo no duplo sentido de: 1-encantar-se, enamorar-se, empolgar-se com o exemplo e a vocação do fundador, tomando-o como referência a ser seguida; 2-encantar-se, espiritualizar-se, contagiar-se espiritualmente pelo seu ethos.

${ }^{22}$ Durkheim (20003, p.239), apesar de analisar o fenômeno religioso numa perspectiva distinta da aqui esboçada, chama a atenção para o fato de que a consciência coletiva de um grupo atua com mais eficiência - portanto, legitima-se melhor - quando "algum órgão claramente definido” no seio da coletividade passa a exercê-la, ao invés de permitir que esta seja exercida de forma difusa.
}

REVISTARELEGENSTHRÉSKEIA - 2020 - UFPR 
sendo ele mesmo essa força - o carisma -, que, nele, pode ser vista, tocada, imitada, referenciada. Assim, podemos compreender como

[...] os fundadores das novas comunidades, a maioria ainda vivos, suscitam veneração e seguimento, despertam as forças individuais de autorrealização, dinamizam um companheirismo radical, cimentado no amor mútuo, dão o devido apreço ao ideal de pobreza, como princípio de recusa do mundo estabelecido, da ordem vigente. Como nos profetas, o carisma, ainda em fase de estruturação, está vivo em toda sua potência, não foi rotinizado e pode ser renovado diante de novas revelações e milagres (MARIZ, 2009, p. 153).

Portanto, pudemos perceber as implicações da crença na existência de um carisma próprio a um líder e de como essa crença, ou desta crença, se produz uma série de representações de uma coletividade sobre si e sobre o líder, que a leva a estruturar-se de modo particular no mundo e no catolicismo, validando ao líder ao mesmo tempo em que se valida; dito de outro modo: percebem no destino do líder o seu próprio destino - quanto mais longe ele for, mais longe a comunidade - nós- irá. Ver a difusão da vocação shalom, por exemplo, no mundo era ver a difusão do trabalho de Moysés, seu êxito, seu acerto; mas era, também e sobretudo, ver o êxito da Comunidade, seu acerto enquanto modo de vida, enquanto identidade; era, para cada um dos membros, o seu próprio acerto enquanto escolha de vida, enquanto vocação.

\section{4-CONSTRUINDO SENTIDOS PARA A PESQUISA: O QUE O PESQUISADOR FAZ, PARA OS SUJEITOS DO CAMPO, AO FAZER UMA PESQUISA?}

Pensar as relações engendradas pela pesquisa sociológica entre os sujeitos do campo e o pesquisador, sobretudo no necessário estabelecimento de relações de empatia/distanciamento dos grupos onde se pesquisa, é uma temática recorrente na Sociologia e na Antropologia de um modo geral. Sabe-se que os nativos "são os depositários das representações sociais que permitirão a construção da empiria desejada para avançar na pesquisa” sobre o universo religioso considerado posto ser a "fonte geradora de experiências e detentora de recortes interpretativos da realidade” (BAPTISTA, 2018, p.23) ${ }^{23}$. Ir em busca da compreensão da experiência vivida pelos sujeitos envolve o ato de deles aproximar-se, engendrando um conjunto de relações que possam ser as mais produtivas para os objetivos da produção de um conhecimento o mais elucidativo acerca da realidade em questão.

\footnotetext{
${ }^{23}$ Como nos lembra Gil (2002), não existe pesquisa qualitativa sem uma observação direta das ações do grupo estudado com o intuito de captar suas explicações e interpretações do campo, o que envolve o contato com os informantes. 
Se é necessário mergulhar na experiência nativa no intuito de compreender o mais legitimamente possível o universo religioso em questão, gozando da confiança dos sujeitos, importa ainda mais guardar a devida distinção entre estar com os nativos, dar-lhes a devida importância no processo de construção do saber sobre seu universo, e tornar-se um deles. A necessária proximidade metodológica (que se opera por meio de observações de campo, entrevistas) não se pode transmutar em proximidade epistemológica, uma vez que se estaria diante de um modus operandi que esgarçaria a necessária relação de alteridade que funda o saber científico. Acerca disso, Silveira nos oferece um esclarecimento fundamental:

\begin{abstract}
"Nativo" refere-se a todos aqueles que vivem uma realidade religiosa, sendo conaturais, imersos nela, não estando preocupados em cultivar distância social, cultural e epistemológica que possibilite desenvolver olhares críticos sobre si mesmo. O "não nativo", ou ainda a outsider perspective, é tudo aquilo que está "fora" da realidade, transitando por ela [...] O jogo entre insider e outsider perspective é o que permite compreender as posições, ideias, discursos e práticas do "nativo" e do "não nativo", bem como o ponto em que elas convergem e divergem. Em linhas gerais, só é possível compreender o "dentro" (familiar, a realidade tida como natural) a partir de deslocamentos para "fora” (2018, p. 164).
\end{abstract}

Tais questões nos foram parecendo mais claras à medida em que encontrávamos pronta aceitação quando de nossa empreitada junto a sujeitos da CCSh para a realização de entrevistas, situações em que uma espécie de “pronto assentimento” parecia desenrolar-se diante de nós. Fomos percebendo, pois, que tal assentimento alicerçava-se numa perspectiva êmica de que a pesquisa poderia cooperar, em certa medida, com alguns elementos do próprio trabalho missionário da CCSh, uma vez que seus membros demonstravam compreensão outra do que viria a ser uma pesquisa sociológica sobre a instituição, distinta daquilo que pensávamos enquanto pesquisadores, e isso obviamente não mais era do que um uso, dos muito possíveis, que aqueles sujeitos faziam de nosso estudo e expertise.

Vejamos, pois, alguns dos sentidos por ele elaborados e que pudemos identificar para os fins da exposição aqui produzida:

Visibilidade da Comunidade na Universidade: a partir dessa imagem, os sujeitos do campo sentiam-se lisonjeados com a realização de uma pesquisa doutoral acerca de seu "modo de ser”, de "sua Comunidade”, de sua “identidade”, o que lhes demonstraria a "importância” da mesma, e de seu fundador, frente ao mundo secular e à Universidade. Se uma pesquisa de doutorado em Sociologia estava sendo realizada, numa universidade pública, sobre a Comunidade é porque esta chegara a tal grau de importância que extrapolara os limites dela mesma. Uma das declarações que podem ilustrar tal imagem é a seguinte: “com certeza a 
Comunidade será muito mais conhecida na Universidade. Isso é muito bom, pois Deus irá alcançar mais pessoas, mais jovens. Muito bom você vir aqui”.

Pode-se perceber, pois, a partir de tal declaração que, percebendo a pesquisa como um “meio" para que a Comunidade se “fizesse conhecer” em importante espaço como é a Universidade, a pesquisa legitimava-se, tendo o membro entrevistado o “dever” de colaboração com a mesma, numa equação que poderia ser resumida assim: a pesquisa aumentará o conhecimento sobre a Comunidade; isso fará a missão da Comunidade ser mais conhecida; sou membro da Comunidade, logo, é meu dever contribuir.

Tal perspectiva, a nosso ver utilitária, foi observável em alguns entrevistados, que empenhavam-se em responder atentamente a cada uma das perguntas que lhes eram feitas. Assim, uma primeira questão que nos apareceu foi: produzir um saber sociológico sobre um grupo religioso sem que seja transformado, necessariamente, num saber do grupo. Entram em cena, aqui, as relações distintas entre um saber sobre o grupo e um saber do grupo. Sociologicamente, não estávamos ali para sermos confundidos com o grupo, mas para compreendermos seu próprio modo de ser aquele grupo.

Auxílio no fazer-memória da história dos membros entrevistados: durante a realização de algumas entrevistas, alguns dos membros esboçaram emoção (chegando mesmo às lágrimas) ao lembrarem-se, diante das perguntas postas, o caminho que haviam percorrido dentro da Comunidade, por eles nomeado como “caminho de salvação”. Era uma reconstrução histórica que faziam durante as entrevistas. O interessante, em termos de pesquisa, era que íamos percebendo como muitos deles não percebiam-se, sobretudo os mais antigos, como "história viva” da Comunidade, tendo dado sua colaboração para a existência da mesma, o que levavaos a, nesse momento, emocionarem-se sobretudo ao verem a longa temporalidade de suas vidas no interior da CCSh, e que passavam, então, a perceberem-se como tal.

Uma entrevistada, por exemplo, depois de chorar, disse o seguinte: “poxa, estou emocionada narrando essas coisas para você. Lembrei de todo meu caminho na Comunidade. Como ela é linda! Me envia esse áudio, quero orar com ele”. Semelhante declaração ouvi de outro entrevistado: "Engraçado, você me perguntando essas coisas me fez lembrar uma série de fatos de minha salvação". Após esses momentos, por duas vezes foi dito o seguinte: "você foi um canal de Deus para me fazer reviver esses fatos”.

Aqui nos aparecia uma segunda questão: a narrativa sociológica elaborada a partir das narrativas dos sujeitos poderia se constituir como uma sociologia existencial objetivamente fundamentada, desde que não se confundisse como a narrativa elaborada pelos membros. Se a 
história ali narrada era “linda” para o entrevistado, ela nos apareceria como "história”, a ser problematizada à luz de tantas outras histórias, lindas ou não, com a qual estaríamos durante a pesquisa.

Esclarecimento de questões "mal entendidas" por outros pesquisadores acerca da Comunidade: os membros da Comunidade mais escolarizados, sobretudo os que se ocupavam do setor de "formação", e que foram por nós entrevistados, como Emmir Nogueira e Josefa Alves (que concluía mestrado em Antropologia quando a entrevista foi realizada), ressaltaram a importância da pesquisa por servir como um “esclarecimento", ou mesmo um "acerto de contas”, com coisas que haviam sido ditas da Comunidade em outros textos acadêmicos e que, segundo elas, “não correspondiam à verdade”, sobretudo informações sobre o fundador, Moysés Azevedo.

Emmir disse o seguinte: "você deve perguntar tudo o que quiser para esclarecer-se, tudo mesmo, para que não sejam ditas as coisas que os professores dizem da Comunidade por não pedirem explicações”. Munidos de tal “ordem nativa”, pusemo-nos a indagar as mais diversas coisas, numa longa entrevista de quase três horas, que gerou, a posteriori, uma relação para além da pesquisa.

Pensamos, assim, que foi percebido, um doutorando em Sociologia da mais importante universidade pública do Ceará, como alguém que poderia “dar voz” ao que seria a "verdade” da Comunidade, e pôr fim a mal-entendidos. Essa imagem nos fez indagar de alguns seminaristas da Comunidade, com os quais nos encontramos ao longo dos três anos de pesquisa, sobre possíveis textos que abordassem a Comunidade, ou seu fundador, em tom pejorativo, mas nenhum deles chegou a confirmar tal informação.

Assim sendo, uma terceira questão versava sobre o tratamento a ser dado às informações recebidas durante uma pesquisa de modo que esta não seja uma mera transcrição daquelas. Pesquisar grupos, sobretudo os religioso, nos põe diante de narrativas que são as oficiais e que, como tal, se pretendem impor sobre seus membros e sobre todos os que venham a ter contato com elas; mas, também, nos leva a considerar narrativas de membros dissidentes ou com sujeitos que antagonizam com a instituição, ficando o pesquisador diante de uma disputa de narrativas que ele precisará administrar. Assim, são vários os sujeitos que visam a pesquisa como "acerto de contas” ou como "ratificação” da voz oficial; daí a importância da busca e análise do pluralismo de vozes.

Colaboração com o arquivo/setor de estudos/memória da Comunidade: à medida em que fomos realizando as entrevistas, sobretudo com pessoas de longa pertença à Comunidade, 
e que formavam um importante "quadro de memória” da mesma, fomos nos tornando conhecidos pelo setor de formação e arquivo da mesma, o que nos fez ser interpelados algumas vezes sobre a possibilidade de ceder os áudios das entrevistas ao setor, sob a alegação de que serviriam para arquivar como fonte de estudos/conhecimentos da Comunidade sobre ela mesma, para as futuras gerações. "É muito importante essa sua pesquisa para que nós nos compreendamos melhor. Tô louca para ver o resultado", disse-nos a bibliotecária. "Você nos ajudará muito, quem é de fora vê melhor as coisas”, afirmou uma consagrada que respondia pelo setor de formação interna.

Apesar de tal possibilidade parecer factual e oportunidade de tornar-me mais próximo deste setor, que poderia nos fornecer mais documentos para a pesquisa ou para outras indagações que surgissem, fomos levado a pensar que apesar da expressa boa intenção, o conjunto de entrevistas poderia vir a constituir-se como um mecanismo de tomada de conhecimento do que havia sido dito pelos entrevistados, sobretudo após o teor da pesquisa vir a público, e constituir-se como um instrumento de controle e/ou punição. Por isso mesmo, resolvemos não fazer a entrega.

Mas, pensamos que aqui nos cabe uma questão bastante pertinente: servirá o texto sociológico como arquivo para as instituições pesquisadas? Como? Por meio de uma atitude que nos leve a entender que o texto deverá ser pensado com a preocupação de tornar-se fonte de pesquisa para outros pesquisadores, daí a importância da objetividade como produto do devido tratamento analítico das fontes, mas podendo, também, servir como arquivo para o universo estudado, sobretudo em se tratando de instituições, como é a Shalom.

Propagação da "ação do Espírito Santo" no mundo através da Comunidade: em sua maioria, os entrevistados que se puseram a tecer considerações sobre o que para eles constituía a "importância da pesquisa”, ressaltaram ser o mecanismo primordial para que o "mundo" conhecesse a "ação do Espírito Santo" a partir de Fortaleza, uma vez que a Comunidade nada mais era do que “a ação do Espírito”. Após a defesa da Tese, uma mestranda em Ciências da Religião, membro da Comunidade, escreveu-nos para solicitar o texto pois precisava relatar, nos EUA (onde morava e cursava o mestrado), como “o Espírito havia agido em Fortaleza, para que os irmãos aqui se maravilhem”. Algo semelhante foi dito por uma entrevistada em Curitiba: "eu creio que a importância de seu trabalho é fazer com que as pessoas saibam como foi o sopro do Espírito Santo em Fortaleza, e de como se irradiou esse sopro pelo mundo”.

Como se pode perceber, mais uma vez se põem as questões em torno do teor do texto sociológico: proselitismo ou análise objetiva? Logo, o que cabe ao texto sociológico é que ele 
não se constitua como mera narrativa ou proselitismo do grupo, servindo de "propagação" do seu universo simbólico, nem como um conjunto de acusações da instituição, caindo num denuncismo vazio. Destacamos isso porque ao mesmo tempo que fomos percebendo essa tentativa de cooptação por parte dos membros da Comunidade, ou de outra compreensão que apresentavam da pesquisa com eles realizados, no meio acadêmico, por sua vez, a recorrente questão posta a nós - "sua pesquisa é contra ou a favor do Shalom?”- nos mostrava a incompreensão também por meio doa pares acadêmicos do que venha a ser uma pesquisa sobre religião, confundindo-a com uma "acusação" pública, cientificamente validada. Ambas as posturas, que podem também estar presentes, a seus modo, no pesquisador, amaçam a boa condução de uma pesquisa.

Instrumento para a "conversão" do pesquisador: por fim, mas não menos importante, a pesquisa foi representada como uma "obra divina” na vida do pesquisador. À medida em que éramos vistos em meio as diversos eventos da Comunidade, durantes as entrevistas, na aquisição de material bibliográfico, nas observações de campo as mais diversas, a ideia de que um "projeto de conversão" ali se desenhava ia tomando a forma de resultado esperado da pesquisa. "De tanto você vir no Shalom você vai acabar sendo um dos nossos”, "você precisa de conversão”, “Deus tá usando essa pesquisa para te converter”, “ainda vou lhe ver pregando”, foram afirmações corriqueiramente ouvidas ao longo dos anos de pesquisa. Uma das secretárias da Diaconia ${ }^{24}$, onde estivemos muitas vezes para realizar as entrevistas, certa vez disse-nos: “meu jovem, com certeza essa pesquisa é uma desculpa de Deus para lhe trazer para junto de nós. Você já foi à missa hoje?”. Para ela, éramos, ou viríamos a ser, um deles. Não haveria outra explicação para tantas idas à sede da Comunidade e aos eventos senão essa ${ }^{25}$.

Ao pensar nesses termos, lembrávamos da temática do "ser afetado" pelos elementos e sujeitos constituintes do campo de pesquisa, tão bem refletido por Fravet-Saada (2005). Ao dizer que os “nativos” adeptos da feitiçaria “exigiam” que ela experimentasse por sua própria conta os "efeitos reais dessa rede particular de comunicação humana em que consiste a feitiçaria”, permitindo-se “ser afetada”, isso implicava não uma identificação epistemológica com “o ponto de vista do nativo”, pois desfaria o projeto de conhecimento antropológico, mas uma oportunidade ímpar de "narrar a experiência” nativa ${ }^{26}$.

\footnotetext{
${ }^{24}$ Nome dado à sede administrativa da Comunidade.

${ }^{25}$ Isso, por certo, não aconteceu, uma vez que as relações estabelecidas com a comunidade eram estritamente de pesquisa, não havendo nem se produzindo relação de identificação com a cosmovisão que orienta seus membros. ${ }^{26}$ Ao apresentar sua experiência etnográfica durante pesquisa com a Comunidade Canção Nova, refletindo a partir do texto de Fravet-Saada, OLIVEIRA expressa o que também pude sentir em meio à CCSs: "Deixar-me afetar por Canção Nova significava deixar-me ‘ser pega' - surpreendida - pelo conteúdo nativo, ou o que quer que ele fosse” REVISTARELEGENSTHRÉSKEIA - 2020 - UFPR
} 
Nesses momentos também nos serviam de reflexão as palavras de ZENOBI (2010, p.471) acerca das relações entre pesquisador e sujeitos do campo:

A construção sistemática dessas relações com o objetivo de conhecer o mundo social edificado por "nossos" nativos costuma ser conflitiva, e as acusações de sermos espiões ou infiltrados recaem frequentemente sobre nós. Isto se deve ao fato de, em certas circunstâncias, nós, antropólogos, sermos considerados sujeitos perigosos, capazes de infligir algum dano às populações com as quais trabalhamos. Normalmente, as suspeitas e acusações sobre nosso trabalho costumam estar relacionadas ao uso que poderíamos fazer do conhecimento construído a partir do trabalho de campo desenvolvido nessas comunidades. Desse modo, elas expressam a preocupação com a relação que este saber irá ter com as pessoas que o tornaram possível ao receberem o pesquisador e ao participarem da pesquisa.

O conflito lembrado pelo autor é perceptível sobretudo porque, em pesquisas sobre religião lida-se o tempo todo com a perspectiva nativa em contraposição à perspectiva do pesquisador, uma vez que estar entre os nativos não deve significar, e muitas vezes não chega a significar, ser um dos nativos. Embora isso seja um tanto claro para os pesquisadores, não o é, nem se chegará a ser, para os nativos. É que, pensamos nós, em se tratando de sujeitos do campo religioso, sobretudo aquelas daquelas religiões que operam na lógica da salvação/conversão (como é o caso da CCSh), é difícil erigir um mundo possível fora da lógica produzida em sua cosmovisão. Falar de nós, nesse sentido, constitui-se para eles como um falar bem de nós, nos auxiliar em nosso trabalho missionário, propagar os feitos de nosso deus. Tornar-se um de nós, portanto. É por meio de desafios tão complexos como estes que os pesquisadores da religião se aventuram, produzindo um (possível) saber sobre campo tão complexo.

\section{5-CONSIDERAÇÕES FINAIS}

Tentamos, no corpo desse artigo, apresentar os percursos de inserção de campo e a discussão teórico-metodológico utilizados durante a realização de uma pesquisa no interior do catolicismo carismático. Seja elencando as idas e vindas em torno da questão norteadora da pesquisa - a constituição da autoridade carismática-, seja ressaltando a importância do campo para definições mais precisas acerca da problemática e da metodologia utilizada, ou mesmo traçando a importância das relações de confiança estabelecidas com os sujeitos (bem como seus

(2014, p. 141). Um desses conteúdos, que posso aqui relatar, foi as reiteradas vezes em que os interlocutores me advertiram que estavam a me passar "coisas bem humanas” acerca da Comunidade, o que não sabiam se "se faziam entender”, dado que a Comunidade, “divina”, é de difícil compreensão “humana”.

REVISTARELEGENSTHRÉSKEIA - 2020 - UFPR 
perigos), apresentamos aqui algumas das dificuldades desse setor de estudos que dialoga, analisa e objetiva crenças que moldam a vida de inúmeros sujeitos.

Ao fim e ao cabo de quatro anos de pesquisa, e pensando hoje sobre os diversos modos de imersão no campo estudado, pudemos compreender como uma gramática de sentidos outros acerca da pesquisa, que poderiam ser (etnocentricamente) tidos como “incompreensão” dos termos de uma perspectiva sociológica do fenômeno religioso por parte dos sujeitos do campo, “contamina” o que poderia vir a ser uma colaboração mais cientificamente legítima dos sujeitos do campo $^{27}$. Ora representando a pesquisa como uma “acusação” de "bisbilhotice” indevida nos assuntos da Comunidade, o que geraria inúmeras negativas de colaboração; ora enxergando nela uma oportunidade de "reprodução" ou "propagação” dos ideais da Comunidade em meio acadêmico, fazendo gerar uma colaboração interessada, pareceu-nos que a sempre buscada objetividade mostrava-se prejudicada se contássemos, apenas, com a narrativa dos sujeitos, o que direcionaria as formas de colaboração destes com o pesquisador.

Se não devíamos contar apenas com essas narrativas, nada faríamos sem essas narrativas. Dado o não-rompimento com sua cosmovisão ${ }^{28}$, questionamentos lançados, perguntas menos convenientes, apresentação de fatos discordantes, dentre outras coisas tendiam a ser percebidos como descréditos à fala nativa e incompreensão do pesquisador nos assuntos “divinos” (necessidade de “ir além do humano”). Era o outro modo de ver a relação, percebida de modo inverso pelo pesquisador: se, para eles, o universo de crença era muito elevado, exigindo do pesquisador um "ir além do humano”; para o pesquisador a realidade ali vivida, de tão naturalizada, não lhes era acessível analiticamente senão pelo desprendimento da visão divinizada, sem uma necessária "vinda ao humano, ao mais embaixo”, ao abandono da visão celestial. Duas perspectivas. Dois saberes. Duas epistemes.

\section{REFERÊNCIAS BIBLIOGRÁFICAS}

BAPTISTA, Saulo de Tarso Cerqueira. Saberes e práticas na pesquisa em Ciências da Religião. In: SILVEIRA, Emerson Sena da (org.). Como estudar religiões: metodologias e estratégias. Petropólis, RJ: Vozes, 2018.

\footnotetext{
${ }^{27}$ Contudo, se assim o fosse, não seriam eles membros do campo científico em vez de membros de uma outra realidade social? A própria ideia de "colaboração legítima”, posta por nós no texto, atua como problematizadora da ideia do que seria tal colaboração. Na verdade, não caberia aos sujeitos tal colaboração; aquela que eles deram é a legítima, ou seja, a expressão de seu modo de existir é o que os legitima como colaboradores, e não autores, da pesquisa.

${ }^{28}$ Que não deve ser exigido deles, pensamos nós, uma vez que, se assim o fizessem deixariam a condição de nativos.
} 
BEAUD, Stéphane; WEBER, Florence. Guia para a pesquisa de campo: produzir e analisar dados etnográficos. Petropolis, RJ: Vozes, 2007.

BERKENBROK, Volney. Mapas lexicais e semânticos - o uso da lexicalidade como metodologia de pesquisa sobre a experiência religiosa In: SILVEIRA, Emerson Sena da (org.). Como estudar religiões: metodologias e estratégias. Petropólis, RJ: Vozes, 2018.

BOURDIEU, Pierre; PASSERON, Jean-Claude; CHAMBOREDON, Jean-Claude. A Profissão de Sociólogo: preliminares epistemológicas. Petropólis, RJ: Vozes, 1999.

CAMPOS, Leonildo Silveira. Novas Comunidades Católicas ou crise do sistema paroquial? Religião e Sociedade, n.30, vol 2, São Paulo, 2010.

CAMPOS, Roberta; MAURICIO JUNIOR, Cleonardo. As formas elementares da liderança carismática: o Verbo e a Imagética da circulação do carisma pentecostal. Mana, vol. 19, n.2, 2013.

CARRANZA, Brenda. Perspectivas da neopentecostalização católica. In: CARRANZA, Brenda; MARIZ, Cecilia; CAMURÇA, Marcelo. Novas Comunidades Católicas: em busca do espaço pós-moderno. Aparecida, SP: Ideias\&Letras, 2009.

Renovação carismática católica: origens, mudanças e tendências:

Aparecida, SP: Santuário, 2000.

FRAVET-SAADA, Jeanne. Ser afetado. Cadernos de Campo, São Paulo, ano 14, n.13, pp. 151-161, 2005.

GEERTZ, Clifford. Nova luz sobre a Antropologia. Rio de Janeiro: Jorge Zahar, 2001.

"Do ponto de vista dos nativos": a natureza do entendimento antropológico" In:

O saber local: novos ensaios em antropologia interpretativa. Petrópolis, RJ: Vozes, 1997.

GIL, Antonio Carlos. Como elaborar projetos de pesquisa. São Paulo: Atlas, 2002.

JUANES, Benigno. Introdução aos carismas. São Paulo: Edições Loyola, 2001.

KAUFFMAN, Jean-Claude. A entrevista compreensiva: um guia para a pesquisa de campo. Petropólis, RJ: Vozes, 2013.

MARIZ, Cecilia. Formas de conceber “comunidades” e "dons” em três vertentes cristãs: analisando rupturas e continuidades. Tempo da Ciência, v.23, n.45, Toledo, 2016.

. Novas Comunidades: por que crescem? In: Novas Comunidades Católicas: em busca do espaço pós-moderno. Aparecida, SP: Ideias\&Letras, 2009.

MIRANDA, Julia. Carisma, sociedade e política: novas linguagens do religioso no político. Rio de Janeiro: Jorge Zahar, 1999.

O’DEA, Thomas. Sociologia da Religião. São Paulo: Biblioteca Pioneira de Ciências Sociais, 1969.

REVISTARELEGENSTHRÉSKEIA - 2020 - UFPR 
OLIVEIRA, Eliane Martins. Semântica da Canção Nova: relações de duplo vínculo e segredo em pesquisas sobre a Comunidade de Vida Canção Nova In: SAFIOTI, Flavio Munhoz (org). Novas Leituras do campo Religioso Brasileiro. Aparecida, SP: Ideias\&Letras, 2014.

PAIS, José Machado. O cotidiano e a prática artesanal da pesquisa. Revista Brasileira de Sociologia. Vol. 1, n.1, jan-jul 2013, Brasília.

PAUGAM, Serge. Afastar-se das pré-noções In: PAUGAM, Serge (coord.). A Pesquisa Sociológica. Petropólis, RJ: Vozes, 2015.

PERDIGÃO, Germana. Os primeiros passos do carisma shalom. Shalom Maná, n.169, julago. 2007, Fortaleza.

ROCCA, Giancarlo. O carisma do fundador. São Paulo: Paulus, 2010.

SAFIOTI, Flavio Munhoz. Elementos sócio-históricos da Renovação Carismática Católica. Estudos de Religião, v.23, n.37, jul/dez. 2009.

SAHLINS, Marshall. Experiência individual e ordem cultural In: SAHLINS, Marshall. Cultura na prática. Rio de Janeiro: EdUFRJ, 2004.

SENNETT, Richard. Autoridade. Rio de Janeiro: Record, 2001.

SILVA, Emanuel Freitas da. A problemática sociológica do carisma: a definição weberiana, apropriações socionatropológicas e um estudo de caso a partir da definição conceitual. Interlegere, v.2, n.24, 2019a. . A constituição carismática de uma autoridade racional: um estudo de caso sobre a Comunidade Católica Shalom. Tese de Doutoramento em Sociologia. Universidade Federal do Ceará. Fortaleza, 2019.

SILVEIRA, Emerson Sena da. Estudo de caso aplicado à religião: entre louvores, corpos, intersubjetividade. In: SILVEIRA, Emerson Sena da. (org.). Como estudar religiões: metodologias e estratégias. Petropólis, RJ: Vozes, 2018.

WEBER, Max. Economia e Sociedade: fundamentos da sociologia compreensiva. 4.ed. Brasília: EdUNB, 2012.

Ensaios de Sociologia. 4.ed. Rio de Janeiro: Zahar Editores, 1979.

WILLAIME, Jean-Paul. Sociologia das Religiões. São Paulo: UNESP, 2012.

ZENOBI, Diego. O antropólogo como "espião": das acusações públicas à construção das perspectivas nativas. Mana, n.16 (2), pp.471-499, 2010 